\title{
Lung-molGPA Index Predicts Survival Outcomes of Non-Small-Cell Lung Cancer Patients with Synchronous or Metachronous Brain Metastases
}

This article was published in the following Dove Press journal: OncoTargets and Therapy

\author{
Kaiyan Chen ${ }^{1-3}$ \\ Fanrong Zhang 1,2,4 \\ Yun Fan ${ }^{1-3}$ \\ Guoping Cheng ${ }^{1,2,5}$
}

'Cancer Hospital of the University of Chinese Academy of Sciences (Zhejiang Cancer Hospital), Hangzhou 310022 , People's Republic of China; ${ }^{2}$ Institute of Cancer and Basic Medicine (IBMC),

Chinese Academy of Sciences, Hangzhou 310022, People's Republic of China; ${ }^{3}$ Department of Thoracic Medical Oncology, Zhejiang Cancer Hospital, Hangzhou 310022, People's Republic of China; ${ }^{4}$ Department of Breast Surgery, Zhejiang Cancer Hospital, Hangzhou 310022, People's Republic of China; ${ }^{5}$ Department of Pathology, Zhejiang Cancer Hospital, Hangzhou 310022 , People's Republic of China
Correspondence: Guoping Cheng

Tel +86 I37 57| 49237

Fax +8657188128254

Email cgpzjhz@I26.com
Background: Graded prognostic assessment for lung cancer using molecular markers (Lung-molGPA) for brain metastases is a powerful prognostic tool. However, it has not been validated for non-small-cell lung cancer (NSCLC) patients with synchronous or metachronous brain metastases.

Methods: A total of 1184 NSCLC patients with synchronous or metachronous brain metastases were reviewed in this study. Comparative clinicopathological variables and survival analysis for these two groups (synchronous vs metachronous), as well as complimentary analysis of prognostic factors for the entire patient cohort, were performed. Afterward, patients were stratified using Lung-molGPA to evaluate the accuracy of the survival estimates.

Results: A total of 763 patients (64.4\%) had synchronous metastases while $35.6 \%$ (421 patients) had metachronous metastasis. Patients with synchronous metastases were more likely to have a smoking history, limited metastatic lesions, and absence of cerebral symptoms $(\mathrm{P}<0.05)$. Patients with metachronous metastatic NSCLC had an overall survival (OS) period of 16.5 (95\% CI 14.5-18.6) months and were longer compared to patients with synchronous metastases (16.5 vs 13.5 [12.5-14.6] months, $\mathrm{P}=0.004)$. In Cox regression multivariable analysis, age $(\mathrm{HR}=1.25, \mathrm{P}=0.008)$, Karnofsky performance status $(\mathrm{HR}=1.30$, $\mathrm{P}=0.005)$, extracranial metastases $(\mathrm{HR}=1.57, \mathrm{P}<0.001)$, number of brain metastases $(\mathrm{HR}=1.22, \mathrm{P}=0.043)$, gene mutation ( $\mathrm{HR}=1.40$ [wild type vs mutation], $\mathrm{P}=0.050 ; \mathrm{HR}=1.42$ [unknown vs mutation], $\mathrm{P}=0.007$ ), and treatment (including TKI, chemotherapy, and local brain treatment, $\mathrm{P}<0.05$ ) were independent prognostic predictors of OS. Additionally, metachronous metastatic patients were at lower risk for disease-related death compared to synchronous metastatic patients $(\mathrm{HR}=0.69, \mathrm{P}<0.001)$. Importantly, median OS stratified by Lung-molGPA of $0-1,1.5-2,2.5-3$ and 3.5-4 scores were 11.0, 14.0, 24.9, and 26.3 months for synchronous brain metastases, and 13.1, 17.0, 37.2, and 66.5 months for metachronous metastases, respectively $(\mathrm{P}<0.001)$.

Conclusion: Lung-molGPA could estimate the prognosis of NSCLC patients with synchronous or metachronous brain metastases. Hence, patients should be carefully stratified for consideration of aggressive therapy.

Keywords: lung-molGPA, non-small-cell lung cancer, synchronous, metachronous, brain metastases

\section{Introduction}

Lung cancer is the leading cause of cancer-related mortality worldwide. ${ }^{1}$ Non-small cell lung cancer (NSCLC) accounts for $85 \%$ of primary lung cancers, with $30-50 \%$ 
of patients developing brain metastases (BM). This substantially affects their quality of life and survival outcomes. $^{2-5}$ Hence, the management of NSCLC patients who present with brain metastases is challenging. Currently, it is unclear if the prognosis of patients with synchronous brain metastasis is better compared to patients who develop brain metastasis later. And a thorough baseline stratification according to this variable had not been fully reported beforehand.

While brain metastases, in general, carry a dismal prognosis, previous studies have suggested that careful selection of NSCLC patients diagnosed with brain metastases may benefit from radical therapeutic modalities such as radiosurgery and surgery. ${ }^{4,6-8}$ Aggressive local treatments (stereotactic radiosurgery [SRS] alone, and surgical resection followed by SRS or whole-brain radiotherapy) for limited metastatic disease have been recommended in the current version of the NCCN-guidelines (www.NCCN. org). Given this recommendation, validated prognostic tools are needed to best select patients for aggressive treatment.

With regards to patients with brain metastases, a recursive partition analysis (RPA) and a graded prognostic assessment (GPA) have been developed and validated to provide clinicians tools to estimate survival. ${ }^{9,10}$ The NSCLC DS-GPA includes the patient age, Karnofsky performance status (KPS), extracranial metastases (ECM), and the number of brain metastases. ${ }^{9}$ Recently was demonstrated that NSCLC patients with EGFR and ALK mutations have markedly improved survival compared to patients without these mutations. ${ }^{11-15}$ Thus, it is essential to determine the effect of $E G F R / A L K$ mutational status on survival outcomes in this population. Soon afterward, an update of the DS-GPA incorporating molecular markers (Lung-molGPA) was proposed. ${ }^{16}$ However, with the recent advent of molecular targeted therapies, the applicability of Lung-molGPA to NSCLC patients with synchronous or metachronous brain metastases has not been defined.

The current retrospective analysis of 1184 patients with brain metastatic NSCLC was designed to examine potential predictive factors for long-term survival outcomes of patients with synchronous and metachronous metastases. Lung-molGPA index was used to predict the prognosis and to enable clinical decision-making for NSCLC patients with synchronous or metachronous brain metastases. Patients should be carefully selected for consideration of curative intent therapy.

\section{Methods and Materials}

\section{Study Population}

We retrospectively collected data from 1184 primary NSCLC patients with brain metastases from October 2007 and December 2015 at Zhejiang Cancer Hospital, China. Studies based on some of the data have been previously published. ${ }^{17}$ In the present study, patients were stratified based on the presence of synchronous or metachronous brain metastases. Synchronous brain metastasis was classified based on the identification of brain metastases during the initial staging Magnetic Resonance Imaging (MRI) scan of the brain, at the time of initial diagnosis. Patients were classified as having metachronous metastases when brain metastases were observed at least three months after the initial diagnosis. The study protocol was approved by the ethical committee of Zhejiang Cancer Hospital, and all patients provided written informed consent.

\section{Data Collection}

Medical records of all NSCLC patients were thoroughly reviewed. Histological types were determined based on the lung tumor classification criteria of the World Health Organization. The TNM stages of patients were determined based on the AJCC eighth edition staging for NSCLC. Patients' characteristics, treatment procedures, and outcomes were obtained using a standardized case report form. Patients were stratified based on the LungmolGPA criteria and then differences between the groups were evaluated. For all patients, pretreatment work-up included fiberoptic bronchoscopy, contrast-enhanced thoracic and upper abdominal computed tomography scan, as well as contrast-enhanced cerebral magnetic resonance imaging. After first-line treatment regarding brain metastases, brain MRI with contrast every three months was used to evaluate the cerebral disease.

\section{Statistical Analysis}

The primary end point was overall survival measured from the diagnosis of brain metastases. Median follow-up time was calculated using the reverse Kaplan-Meier method. Patient demographics, brain metastasis characteristics and cerebral symptoms were compared using the chi-square test or Fisher's exact test. Kaplan-Meier estimates of the OS were performed for the entire cohort, and then subgroups were compared using the Log rank test. Single variable analysis for factors affecting OS was performed 
using Cox proportional hazards modeling. Variables determined to be predictive for OS $(\mathrm{P}<0.05)$ were used in the multivariable Cox proportional hazards model in a forward stepwise manner. Statistical analyses were performed using SPSS version 20.0 (Chicago, IL) and GraphPad Prism (version 7.01). Statistical significance was considered when $\mathrm{p} \leq 0.05$ using a two-sided test.

\section{Results}

\section{Demographics and Clinical}

\section{Characteristics}

The demographics characteristics of the 1184 enrolled patients have been previously published. ${ }^{17}$ Complementing previously published data, $72.0 \%$ of patients were administered systemic chemotherapy, while $47.5 \%$ received TKI treatment. The median size of the largest brain metastasis in each case was $1.4 \mathrm{~cm}$ $(0.2-7.8 \mathrm{~cm})$. In addition, $40.9 \%(484)$ of the patients had different levels of symptomatic brain metastases. Moreover, 64.4\% (763 patients) had synchronous metastases and 35.6\% (421 patients) had metachronous metastasis. Both groups were well balanced for most of the clinical criteria (gender, age, KPS, histology, gene mutation, ECM, and the rate of chemotherapy). However, patients with synchronous occurrence of metastases were significantly more likely to have a smoking history, limited metastatic lesions, absence of neurologic symptoms, and underwent fewer therapeutic modalities, including TKI and local brain therapy $(\mathrm{P}<0.05)$. Patient characteristics of these two groups are shown in Table 1.

\section{Survival Outcomes}

The median follow-up period was 57.0 months $(95 \% \mathrm{CI}$ 54.3-59.7), with $86.6 \%$ of patients dying before study analysis. With regards to patients with metachronous metastases, the median interval between the initial diagnosis of NSCLC and the detection of metastatic disease was 13.2 months (range 3.0-57.0 months). Kaplan-Meier curves showed that NSCLC patients with metachronous metastases had an OS period of 16.5 (95\% CI 14.5-18.6) months, which was longer compared to patients with synchronous metastases (16.5 vs 13.5 [12.5-14.6] months, $\mathrm{P}=0.004$, Figure 1). The 1 -year-OS rates were $61.6 \%$ and $55.9 \%$, respectively. Univariate Cox regression analysis demonstrated that female patients, younger patients, no smoking history, higher KPS, fewer brain metastases, adenocarcinoma histology, driver-gene mutation, absence of
ECM, received TKI strategies and local brain therapy, as well as chemotherapy were all significantly associated with decreased risk of death $(\mathrm{P}<0.05$, Table 2$)$. However, no statistically significant difference regarding OS was observed between the patients with cerebral symptoms or not $(\mathrm{P}=0.209$, Table 2$)$. In multivariable analysis, age $(\mathrm{HR}=1.25, \mathrm{P}=0.008)$, KPS $(\mathrm{HR}=1.30, \mathrm{P}=0.005), \mathrm{ECM}$ $(\mathrm{HR}=1.57, \quad \mathrm{P}<0.001)$, number of brain metastases $(\mathrm{HR}=1.22, \mathrm{P}=0.043)$, gene mutation $(\mathrm{HR}=1.40$ [wild type vs mutation], $\mathrm{P}=0.050 ; \mathrm{HR}=1.42$ [unknown vs mutation], $\mathrm{P}=0.007$ ), and treatments (including TKI, and chemotherapy, and local brain treatment, $\mathrm{P}<0.05$ ) were independent prognostic predictors of OS (Table 2). Notably, metachronous metastatic patients had a lower risk for diseaserelated death than those with synchronous metastases (HR $=0.69,95 \%$ CI: 0.58-0.84, $\mathrm{P}<0.001$; Table 2).

\section{Lung-molGPA for NSCLC Patients with Synchronous or Metachronous Brain Metastases}

Kaplan-Meier plot of OS is shown in Figure 2 after LungmolGPA index stratification. For NSCLC patients with synchronous metastases, the median OS based on stratified Lung-molGPA scores of $0-1,1.5-2,2.5-3$ and 3.5-4 were 11.0, 14.0, 24.9, and 26.3 months, respectively $(\mathrm{P}<0.001$, Figure 2A). For NSCLC patients with metachronous metastases, the median OS based on stratified LungmolGPA scores of $0-1,1.5-2,2.5-3$ and $3.5-4$ were 13.1, 17.0, 37.2, and 66.5 months, respectively $(\mathrm{P}<0.001$, Figure 2B). The median OS for the most favorable group (metachronous group with 3.5-4 score) was 66.5 months.

\section{Discussion}

In this study, we specifically addressed the relevance of synchronous and metachronous brain metastases as it relates to prognosis in a large cohort of NSCLC patients. In addition, we determined their association with clinicopathological variables and survival. The Lung-molGPA index was used to estimate the prognosis of patients with synchronous or metachronous metastases. This could help to identify patients who may benefit from intensified therapy.

NSCLC patients were more likely to have synchronous brain metastases compared to metachronous metastases $(64.4 \%$ vs $35.6 \%)$. Patients with synchronous metastases were more likely to have a smoking history, limited metastatic lesions, and absence of cerebral symptoms. Retrospective analysis indicated that 
Table I Clinicopathological Features of NSCLC Patients with Synchronous vs Metachronous Brain Metastases

\begin{tabular}{|c|c|c|c|c|}
\hline Parameters & All Cases & Synchronous & Metachronous & P-value \\
\hline Total & 1184 & 763 (64.4\%) & 421 (35.6\%) & \\
\hline \multicolumn{5}{|l|}{ Gender } \\
\hline Male & $688(58.1 \%)$ & $458(60.0 \%)$ & $230(54.6 \%)$ & 0.072 \\
\hline Female & 496 (4I.9\%) & 305 (40.0\%) & 191 (45.4\%) & \\
\hline \multicolumn{5}{|l|}{ Age, year } \\
\hline$<65$ & 961 (8I.2\%) & 608 (79.7\%) & 353 (83.8\%) & 0.080 \\
\hline$\geq 65$ & $223(18.8 \%)$ & 155 (20.3\%) & $68(16.2 \%)$ & \\
\hline \multicolumn{5}{|l|}{ Smoking status } \\
\hline Never & 638 (53.9\%) & $386(50.6 \%)$ & 252 (59.9\%) & 0.002 \\
\hline Ever/current & $546(46.1 \%)$ & 377 (49.4\%) & $169(40.1 \%)$ & \\
\hline \multicolumn{5}{|l|}{ KPS } \\
\hline$\geq 70$ & 792 (66.9\%) & $511(67.0 \%)$ & $28 \mathrm{I}(66.7 \%)$ & 0.937 \\
\hline$<70$ & $392(33.1 \%)$ & $252(33.0 \%)$ & 140 (33.3\%) & \\
\hline \multicolumn{5}{|l|}{ Brain metastases, No. } \\
\hline $1-3$ & $816(68.9 \%)$ & 544 (7I.3\%) & $272(64.6 \%)$ & 0.023 \\
\hline$>3$ & $350(29.6 \%)$ & 209 (27.4\%) & |4| (33.5\%) & \\
\hline Missing & 18 (1.5\%) & $10(1.3 \%)$ & $8(1.9 \%)$ & \\
\hline \multicolumn{5}{|l|}{ Histology subtype } \\
\hline Adenocarcinoma & 924 (78.0\%) & 589 (77.2\%) & 335 (79.6\%) & 0.137 \\
\hline Non-adenocarcinoma & 259 (21.9\%) & 173 (22.7\%) & 86 (20.4\%) & \\
\hline Missing & I (0.I\%) & I (0.1\%) & $0(0.0 \%)$ & \\
\hline \multicolumn{5}{|l|}{ Mutation status } \\
\hline EGFR/ALK & $25 \mathrm{I}(2 \mathrm{I} .2 \%)$ & 170 (22.3\%) & 81 (19.2\%) & 0.365 \\
\hline Wild-type & 170 (14.4\%) & $104(13.6 \%)$ & $66(15.7 \%)$ & \\
\hline Unknown & 763 (64.4\%) & 489 (64.1\%) & $274(65.1 \%)$ & \\
\hline \multicolumn{5}{|l|}{ ECM } \\
\hline No & 407 (34.4\%) & 266 (34.9\%) & |4| (33.5\%) & 0.652 \\
\hline Yes & $773(65.3 \%)$ & 495 (64.9\%) & $278(66.0 \%)$ & \\
\hline Missing & $4(0.3 \%)$ & $2(0.2 \%)$ & $2(0.5 \%)$ & \\
\hline \multicolumn{5}{|l|}{ Cerebral Symptoms } \\
\hline No & $616(52.0 \%)$ & 421 (55.2\%) & 195 (46.3\%) & $<0.001$ \\
\hline Yes & $484(40.9 \%)$ & $279(36.6 \%)$ & 205 (48.7\%) & \\
\hline Missing & $84(7.1 \%)$ & $63(8.2 \%)$ & $21(5.0 \%)$ & \\
\hline \multicolumn{5}{|c|}{ Local treatment (Surgery/WBRT/SRS) } \\
\hline No & $283(23.9 \%)$ & $218(28.6 \%)$ & $65(15.5 \%)$ & $<0.001$ \\
\hline Yes & 885 (74.7\%) & 535 (70.1\%) & $350(83.1 \%)$ & \\
\hline Missing & $16(1.4 \%)$ & $10(1.3 \%)$ & $6(1.4 \%)$ & \\
\hline \multicolumn{5}{|l|}{ TKI therapy } \\
\hline No & $622(52.5 \%)$ & $416(54.5 \%)$ & $206(48.9 \%)$ & $<0.001$ \\
\hline
\end{tabular}

(Continued) 
Table I (Continued).

\begin{tabular}{|l|l|l|l|l|}
\hline Parameters & All Cases & Synchronous & Metachronous & P-value \\
\hline Yes & $562(47.5 \%)$ & $347(45.5 \%)$ & $215(51.1 \%)$ & \\
\hline Chemotherapy & $332(28.0 \%)$ & $163(21.4 \%)$ & $169(40.1 \%)$ & 0.065 \\
\hline No & $852(72.0 \%)$ & $600(78.6 \%)$ & $252(59.9 \%)$ & \\
Yes &
\end{tabular}

Note: Bold text: $\mathrm{P}<0.05$.

Abbreviations: ECM, extracranial metastases; KPS, Karnofsky performance status; NSCLC, non-small-cell lung cancer; SRS, stereotactic radiosurgery; TKI, tyrosine kinase inhibitor, WBRT, whole-brain radiation therapy.

cumulative pack-years of smoking was associated with higher brain metastasis velocity and greater neurologic death than non-smokers. ${ }^{18}$ It has been hypothesized that smoking may contribute to the development of a more aggressive cancer phenotype through the activation of multiple signaling pathways and an increase in the mutational load. ${ }^{19}$ Moreover, smoking has the potential to substantially deprive overall cancer treatment outcomes through increased treatment-related toxicity, treatment failure, and comorbid disease and worsen survival. Accordingly, for patients with metastatic disease undergoing a curative management, smoking cessation should be suggested. In addition, compared to patients with metachronous brain metastases, patients with synchronous metastases had an absence of brain symptoms. This may be due to the lower number of lesions and shorter disease onset time. Consequently, clinicians should perform enhanced brain MRI examinations at

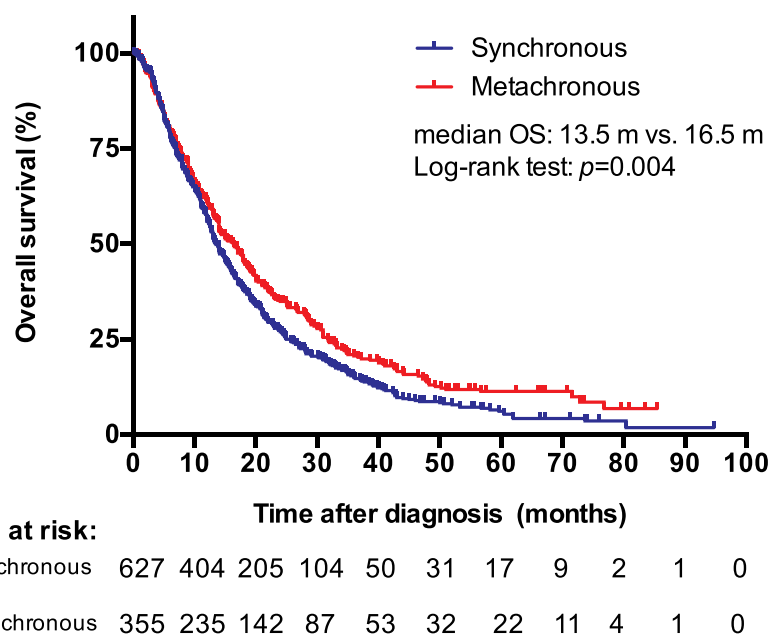

Figure I Kaplan-Meier survival curves based on brain metastatic time for patients with non-small-cell lung cancer (NSCLC). NSCLC patients with metachronous metastases had a longer overall survival (OS) compared to patients with synchronous metastases ( 16.5 vs 13.5 months, $\mathrm{P}=0.004$ ). the initial diagnosis of lung cancer regardless of whether patients showed symptoms of brain metastases.NSCLC patients with brain metastasis at initial diagnosis had an unfavorable prognosis compared to patients with metastatic recurrence later (OS: 13.5 vs 16.5 months, $\mathrm{P}=0.004)$. This suggests that NSCLC patients with metachronous metastases may benefit from ablative therapies including radiosurgery and surgery. ${ }^{4,6,7,20}$ Previous studies have also demonstrated that patients with synchronous brain metastases have a poorer prognosis compared to patients who subsequently develop brain metastases. ${ }^{6,7,21}$ In a retrospective study, Flannery et al reported patients with metachronous solitary brain metastases had a significant median survival advantage compared to those with synchronous metastases. ${ }^{6}$ Similarly, Zabel et al showed that median survival rates for patients with metachronous metastases was obviously higher than patients with synchronous metastases. ${ }^{7}$ However, c comparisons across different studies are difficult due to the small sample cohorts in published studies. Some of these studies compared patients with synchronous vs metachronous metastases and found no differences in median OS. ${ }^{8,22}$ Synchronous and metachronous metastases classify two vastly different clinical scenarios. For patients with synchronous metastatic NSCLC, most often a significant tumor burden is present and treatment of the metastatic site and multimodal treatment of the primary tumor have to be integrated in a reasonable manner. ${ }^{5}$ The favorable survival rates of NSCLC patients with metachronous metastases encourages the use of aggressive, ablative therapy for selected patients. ${ }^{23}$ NSCLC patients with metachronous brain metastasis have longer survival times compared to patients with synchronous metastases. Hence, it may be beneficial to classify patients who may benefit from intensified therapy. 
Table 2 Univariate and Multivariate Cox Regression Analyses of Prognostic Factors for Survival in NSCLC Patients with Brain Metastases

\begin{tabular}{|c|c|c|c|c|}
\hline \multirow[t]{2}{*}{ Parameters } & \multicolumn{2}{|c|}{ Univariate Analysis } & \multicolumn{2}{|c|}{$\begin{array}{l}\text { Multivariate } \\
\text { Analysis }\end{array}$} \\
\hline & $\begin{array}{l}\text { HR }(95 \% \\
\text { CI) }\end{array}$ & P-value & $\begin{array}{l}\text { HR }(95 \% \\
\text { CI) }\end{array}$ & P-value \\
\hline \multicolumn{5}{|l|}{ Gender } \\
\hline $\begin{array}{l}\text { Male } \\
\text { Female }\end{array}$ & $\begin{array}{l}1.00 \\
0.87 \\
(0.76-1.00)\end{array}$ & 0.042 & & \\
\hline \multicolumn{5}{|l|}{ Age, year } \\
\hline $\begin{array}{l}<65 \\
\geq 65\end{array}$ & $\begin{array}{l}1.00 \\
1.56 \\
(1.32-1.84)\end{array}$ & $<0.001$ & $\begin{array}{l}1.00 \\
1.25 \\
(1.06-1.48)\end{array}$ & 0.008 \\
\hline \multicolumn{5}{|l|}{ Smoking status } \\
\hline $\begin{array}{l}\text { Never } \\
\text { Ever/current }\end{array}$ & $\begin{array}{l}1.00 \\
1.23 \\
(1.08-1.41)\end{array}$ & 0.002 & & \\
\hline \multicolumn{5}{|l|}{ KPS } \\
\hline $\begin{array}{l}0-1 \\
2\end{array}$ & $\begin{array}{l}1.00 \\
1.38 \\
(1.19-1.59)\end{array}$ & $<0.001$ & $\begin{array}{l}1.00 \\
1.30 \\
(1.08-1.57)\end{array}$ & 0.005 \\
\hline \multicolumn{5}{|c|}{ Brain metastases, No. } \\
\hline $\begin{array}{l}\mathrm{I}-3 \\
>3\end{array}$ & $\begin{array}{l}1.00 \\
1.49 \\
(1.29-1.73)\end{array}$ & 0.004 & $\begin{array}{l}1.00 \\
1.22 \\
(1.01-1.48)\end{array}$ & 0.043 \\
\hline \multicolumn{5}{|l|}{ Histology subtype } \\
\hline $\begin{array}{l}\text { Adenocarcinoma } \\
\text { Non- } \\
\text { adenocarcinoma }\end{array}$ & $\begin{array}{l}1.00 \\
1.36 \\
(1.16-1.59)\end{array}$ & $<0.001$ & & \\
\hline \multicolumn{5}{|l|}{ Mutation status } \\
\hline $\begin{array}{l}\text { EGFR/ALK } \\
\text { Wild-type }\end{array}$ & $\begin{array}{l}1.00 \\
1.78 \\
(1.41-2.26)\end{array}$ & $<0.001$ & $\begin{array}{l}1.00 \\
1.40 \\
(1.00-1.96)\end{array}$ & 0.050 \\
\hline Unknown & $\begin{array}{l}1.89 \\
(1.58-2.26)\end{array}$ & $<0.001$ & $\begin{array}{l}1.42 \\
(1.10-1.83)\end{array}$ & 0.007 \\
\hline \multicolumn{5}{|l|}{ ECM } \\
\hline $\begin{array}{l}\text { No } \\
\text { Yes }\end{array}$ & $\begin{array}{l}1.00 \\
1.24 \\
(1.07-1.44)\end{array}$ & $<0.001$ & $\begin{array}{l}1.00 \\
1.57 \\
(1.30-1.90)\end{array}$ & $<0.001$ \\
\hline \multicolumn{5}{|c|}{ Cerebral Symptoms } \\
\hline No & 1.00 & & & \\
\hline
\end{tabular}

(Continued)
Table 2 (Continued).

\begin{tabular}{|c|c|c|c|c|}
\hline \multirow[t]{2}{*}{ Parameters } & \multicolumn{2}{|c|}{ Univariate Analysis } & \multicolumn{2}{|c|}{$\begin{array}{l}\text { Multivariate } \\
\text { Analysis }\end{array}$} \\
\hline & $\begin{array}{l}\text { HR }(95 \% \\
\mathrm{CI})\end{array}$ & P-value & $\begin{array}{l}\text { HR }(95 \% \\
\text { CI) }\end{array}$ & P-value \\
\hline Yes & $\begin{array}{l}1.01 \\
(0.95-1.25)\end{array}$ & 0.209 & & \\
\hline \multicolumn{2}{|c|}{$\begin{array}{l}\text { Local treatment (Surgery } \\
+ \text { WBRT+SRS) }\end{array}$} & & & \\
\hline $\begin{array}{l}\text { No } \\
\text { Yes }\end{array}$ & $\begin{array}{l}1.00 \\
0.63 \\
(0.54-0.74)\end{array}$ & $<0.001$ & $\begin{array}{l}1.00 \\
0.84 \\
(0.7 I-0.99)\end{array}$ & 0.038 \\
\hline \multicolumn{5}{|l|}{ TKI therapy } \\
\hline $\begin{array}{l}\text { No } \\
\text { Yes }\end{array}$ & $\begin{array}{l}1.00 \\
0.39 \\
(0.34-0.45)\end{array}$ & $<0.001$ & $\begin{array}{l}1.00 \\
0.34 \\
(0.28-0.42)\end{array}$ & $<0.001$ \\
\hline \multicolumn{5}{|l|}{ Chemotherapy } \\
\hline $\begin{array}{l}\text { No } \\
\text { Yes }\end{array}$ & $\begin{array}{l}1.00 \\
0.72 \\
(0.6 \mathrm{I}-0.83)\end{array}$ & $<0.001$ & $\begin{array}{l}1.00 \\
0.53 \\
(0.43-0.65)\end{array}$ & $<0.001$ \\
\hline \multicolumn{5}{|l|}{ BM status } \\
\hline $\begin{array}{l}\text { Synchronous } \\
\text { Metachronous }\end{array}$ & $\begin{array}{l}1.00 \\
0.81 \\
(0.7 I-0.94)\end{array}$ & 0.004 & $\begin{array}{l}1.00 \\
0.69 \\
(0.58-0.84)\end{array}$ & $<0.001$ \\
\hline
\end{tabular}

Note: Bold text: $P<0.05$.

Abbreviations: BM, brain metastases; ECM, extracranial metastases; HR, hazard ratio; KPS, Karnofsky performance status; NSCLC, non-small-cell lung cancer; SRS, stereotactic radiosurgery; TKI, tyrosine kinase inhibitor; WBRT, whole-brain radiation therapy.

The Lung-molGPA index has been validated for the management of brain metastases and is a tool well suited for decision making. ${ }^{16}$ The present study determined the effect of $E G F R / A L K$ mutational status on survival outcomes. Significant prognostic factors included the original five factors (patient age, performance status, ECM, number of metastases, and gene status) used for the Lung-molGPA index in addition to metachronous brain metastasis. Notably, metachronous metastasis was independently associated with significantly higher $\mathrm{OS}(\mathrm{HR}=0.69, \mathrm{P}<0.001)$. Additionally, the Lung-molGPA index provided an accurate prediction of survival rates in the two patient groups. Patients with metachronous metastases had better OS compared to patients with synchronous brain metastases for each stratified class score of $0-1,1.5-2,2.5-3$ and 3.5-4, respectively. The best median OS was 66.5 months for patients in the 


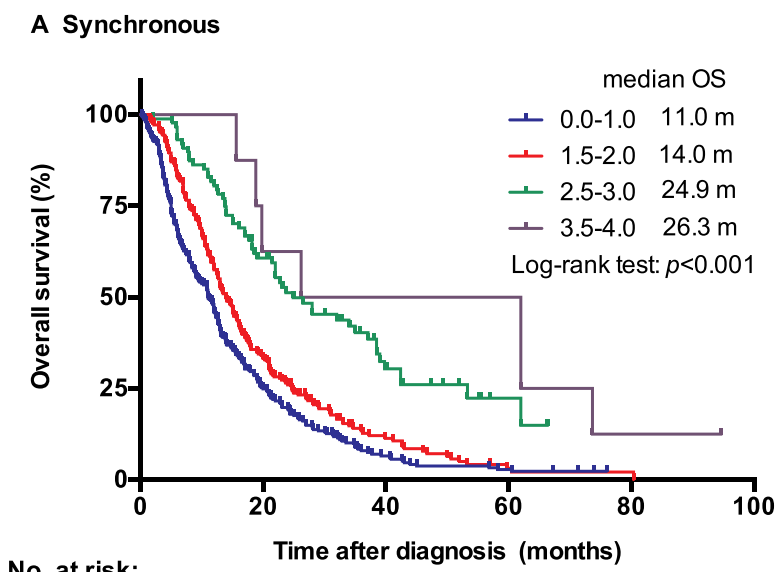

No. at risk:

$\begin{array}{lcccccc}\mathbf{0}-1.0 & 285 & 68 & 13 & 5 & 0 & 0 \\ \mathbf{1 . 5}-2.0 & 247 & 81 & 16 & 3 & 0 & 0 \\ \mathbf{2 . 5}-3.0 & 87 & 48 & 14 & 2 & 0 & 0 \\ \mathbf{3 . 5}-4.0 & 8 & 5 & 4 & 3 & 1 & 0\end{array}$

\section{B Metachronous}

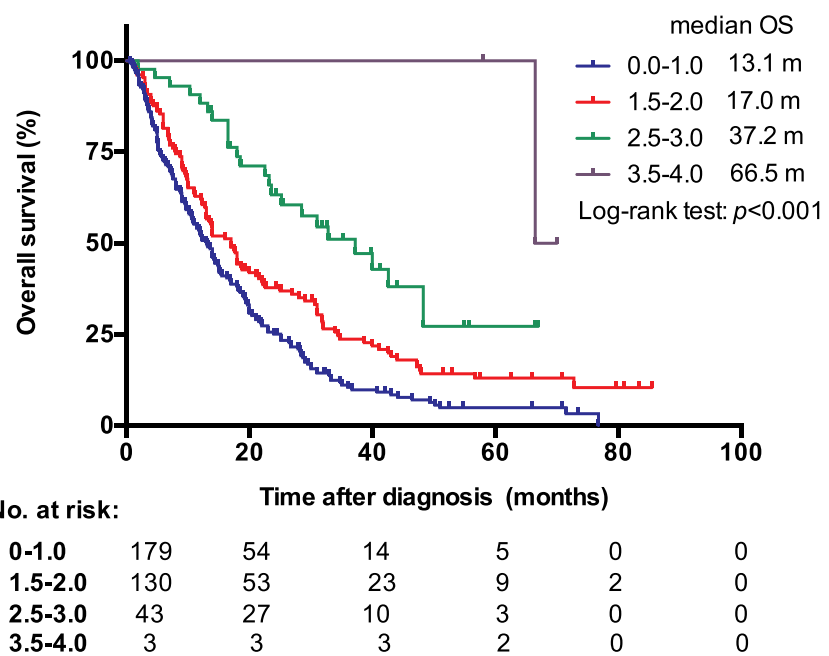

Figure 2 Kaplan-Meier survival curves based on the Lung-molGPA index for non-small-cell lung cancer (NSCLC) patients with synchronous or metachronous brain metastases. (A) Among NSCLC patients with synchronous metastases, the median overall survival (OS) based on stratified Lung-molGPA scores of 0-I, I.5-2, 2.5-3 and 3.5-4 were II.0, 14.0, 24.9, and 26.3 months, respectively $(\mathrm{P}<0.00 \mathrm{I})$. (B) With regards to NSCLC patients with metachronous metastases, the median OS based on stratified Lung-molGPA scores of $0-1,1.5-2,2.5-3$ and 3.5-4 were I3.I, 17.0, 37.2, and 66.5 months, respectively $(P<0.00 I)$.

metachronous metastases group with a stratified class score of 3.5-4. Hence, the present study demonstrated that the survival estimates calculated using Lung-molGPA were accurate for patients with synchronous and metachronous brain metastases. These results suggest that careful case selection is crucial in determining an aggressive treatment approach for patients with brain metastases.

To our knowledge, this is the largest study that evaluated survival outcomes in NSCLC patients with synchronous or metachronous occurrence of brain metastases. NSCLC patients with metachronous brain metastases had a more favorable prognosis compared to patients with synchronous metastases in the brain. However, our study had several limitations. This was a retrospective study and hence could have had a significant bias that affected our results. There may have been inhomogeneity in the analyzed group of patients with respect to locoregional tumor extent, the involvement of metastatic sites, the number of brain metastases, the degree of brain edema, and the administered treatments. In addition, our patient cohort was small and was derived from a single institution.

\section{Conclusion}

Lung-molGPA can predict survival and suits for both groups of NSCLC patients, with synchronous and metachronous metastases, which helps identify patients who are most likely to benefit from ablative therapy.

\section{Data Sharing Statement}

All relevant data are within the paper.

\section{Funding}

This study was supported by the grant from the Zhejiang Public Welfare Technology Research Program (No. LGF20H160008).

\section{Disclosure}

The authors declare that they have no conflict of interest related to this work.

\section{References}

1. Siegel RL, Miller KD, Jemal A. Cancer statistics, 2020. CA Cancer J Clin. 2020;70(1):7-30.

2. Sul J, Posner JB. Brain metastases: epidemiology and pathophysiology. Cancer Treat Res. 2007;136:1-21.

3. Zhang F, Zheng W, Ying L, et al. A nomogram to predict brain metastases of resected non-small cell lung cancer patients. Ann Surg Oncol. 2016;23(9):3033-3039.

4. Niglas M, Cheung P. Ablative therapy in oligometastatic non-small cell lung cancer-an editorial on recent evidence. $J$ Thorac Dis. 2018;10 (1):138-140.

5. Simoff MJ, Lally B, Slade MG, et al. Symptom management in patients with lung cancer: diagnosis and management of lung cancer, 3rd ed: American College of Chest Physicians evidence-based clinical practice guidelines. Chest. 2013;143(5 Suppl):e455S-e497S.

6. Flannery TW, Suntharalingam M, Kwok Y, et al. Gamma knife stereotactic radiosurgery for synchronous versus metachronous solitary brain metastases from non-small cell lung cancer. Lung Cancer. 2003;42 (3):327-333. 
7. Zabel A, Milker-Zabel S, Thilmann C, et al. Treatment of brain metastases in patients with non-small cell lung cancer (NSCLC) by stereotactic linac-based radiosurgery: prognostic factors. Lung Cancer. 2002;37(1):87-94.

8. Fleckenstein J, Petroff A, Schafers HJ, Wehler T, Schope J, Rube C. Long-term outcomes in radically treated synchronous vs. metachronous oligometastatic non-small-cell lung cancer. BMC Cancer. 2016;16:348.

9. Sperduto PW, Kased N, Roberge D, et al. Summary report on the graded prognostic assessment: an accurate and facile diagnosis-specific tool to estimate survival for patients with brain metastases. J Clin Oncol. 2012;30(4):419-425.

10. Gaspar L, Scott C, Rotman M, et al. Recursive partitioning analysis (RPA) of prognostic factors in three Radiation Therapy Oncology Group (RTOG) brain metastases trials. Int J Radiat Oncol Biol Phys. 1997;37(4):745-751.

11. Soria JC, Ohe Y, Vansteenkiste J, et al. Osimertinib in untreated EGFR-mutated advanced non-small-cell lung cancer. $N$ Engl J Med. 2018;378(2):113-125.

12. Shaw AT, Felip E, Bauer TM, et al. Lorlatinib in non-small-cell lung cancer with ALK or ROS1 rearrangement: an international, multicentre, open-label, single-arm first-in-man phase 1 trial. Lancet Oncol. 2017;18(12):1590-1599.

13. Schuler M, Wu YL, Hirsh V, et al. First-line afatinib versus chemotherapy in patients with non-small cell lung cancer and common epidermal growth factor receptor gene mutations and brain metastases. J Thorac Oncol. 2016;11(3):380-390.

14. Gadgeel SM, Gandhi L, Riely GJ, et al. Safety and activity of alectinib against systemic disease and brain metastases in patients with crizotinib-resistant ALK-rearranged non-small-cell lung cancer (AF-002JG): results from the dose-finding portion of a phase $1 / 2$ study. Lancet Oncol. 2014;15(10):1119-1128.
15. Dempke WC, Edvardsen K, Lu S, Reinmuth N, Reck M, Inoue A. Brain metastases in NSCLC - are TKIs changing the treatment strategy? Anticancer Res. 2015;35(11):5797-5806.

16. Sperduto PW, Yang TJ, Beal K, et al. Estimating survival in patients with lung cancer and brain metastases: an update of the graded prognostic assessment for Lung Cancer Using Molecular Markers (Lung-molGPA). JAMA Oncol. 2017;3(6):827-831.

17. Chen K, Yu X, Zhang F, et al. Applicability of the lung-molGPA index in non-small cell lung cancer patients with different gene alterations and brain metastases. Lung Cancer. 2018;125:8-13.

18. Shenker RF, McTyre ER, Ruiz J, et al. The effects of smoking status and smoking history on patients with brain metastases from lung cancer. Cancer Med. 2017;6(5):944-952.

19. Warren GW, Sobus S, Gritz ER. The biological and clinical effects of smoking by patients with cancer and strategies to implement evidence-based tobacco cessation support. Lancet Oncol. 2014;15 (12):e568-e580.

20. Song A, Lu B. Utility of stereotactic ablative radiotherapy/stereotactic body radiation therapy in the setting of oligometastatic non-small cell lung cancer. $J$ Thorac Dis. 2018;10(2):657-660.

21. Ashworth AB, Senan S, Palma DA, et al. An individual patient data metaanalysis of outcomes and prognostic factors after treatment of oligometastatic non-small-cell lung cancer. Clin Lung Cancer. 2014;15(5):346-355.

22. Shibahara I, Kanamori M, Watanabe T, et al. Clinical features of precocious, synchronous, and metachronous brain metastases and the role of tumor resection. World Neurosurg. 2018;113:e1-e9.

23. Kim C, Hoang CD, Kesarwala AH, Schrump DS, Guha U, Rajan A. Role of local ablative therapy in patients with oligometastatic and oligoprogressive non-small cell lung cancer. J Thorac Oncol. 2017;12 (2):179-193.

\section{Publish your work in this journal}

OncoTargets and Therapy is an international, peer-reviewed, open access journal focusing on the pathological basis of all cancers, potential targets for therapy and treatment protocols employed to improve the management of cancer patients. The journal also focuses on the impact of management programs and new therapeutic agents and protocols on patient perspectives such as quality of life, adherence and satisfaction. The manuscript management system is completely online and includes a very quick and fair peer-review system, which is all easy to use. Visit http://www.dovepress.com/ testimonials.php to read real quotes from published authors. 